\title{
DIRETAS JÁ, UM MOVIMENTO SOCIAL HÍBRIDO
}

Sonale Diane Pastro Oliveira

Maria Gabriela da Silva Martins da Cunha Marinho

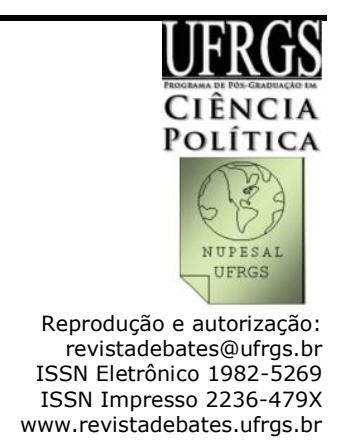

\section{Resumo}

Após longo período de sufocamento político, o processo de redemocratização mostrou-se terreno fértil para o renascimento dos movimentos sociais na América Latina. Os novos atores que emergiram à cena política na década de 1980 trouxeram para o debate novos e velhos referenciais de luta popular, caracterizando o que estudiosos do tema têm denominado movimentos sociais híbridos. Dentro dessa perspectiva, pretendemos analisar a Campanha Diretas, Já!, ocorrida no Brasil em 1984, buscando apreender seu hibridismo à partir do resgate de suas permanências e dos novos elementos que singularizam as mobilizações populares da segunda metade do século XX.

Palavras-chave: Redemocratização; Movimento Social; Sujeito Coletivo; Hibridismo; Diretas Já.

\begin{abstract}
After a long period of political suffocation, the democratization process has remained as a fertile ground for the renaissance of American Latin social movements. The new characters, who emerged from the political scene in the 1980 's, have arisen new and old popular class struggle to the debate. This debate has characterized what scholars name as social hybrid movements.

Inside this perspective, we intend to analyse the popular campaign "Diretas Já!" (it was a campaign that asked the right for all the citizens to vote) which occurred in Brazil in 1984. This analysis attempts to understand the hybridism from the remains to the new elements that has made the popular mobilization unique through the second half of the XX century.
\end{abstract}

Keywords: Redemocratization; Social Movement; Collective Individuals; Hybridism; "Diretas Já". 


\section{Introdução}

A partir da década de 1960, nos países centrais, uma nova sociedade parece ter emergido em decorrência das intensas transformações geradas pela Revolução Tecnocientífica e cujo impacto passaria a ser sentido em todos os setores da experiência humana. A chamada sociedade pós-industrial - assim denominada em 1973 pelo sociólogo norte-americano Daniel Bell em sua obra mais conhecida, $O$ Advento da Sociedade Pós-Industrial (1977, na versão brasileira) - passou a ser percebida como fundada em valores não materiais. Ao mesmo tempo, a emergência de novos movimentos e atores sociais - mobilização estudantil, por direitos civis, de homossexuais, de minorias étnicas, ambientalistas, feministas, entre outros - assinalou a busca por uma democracia renovada.

No contexto desses novos arranjos, fragilizou-se o modo pelo qual as lutas políticas eram travadas em seus espaços habituais e em torno de demandas históricas, como as reivindicações sindicais e trabalhistas ou os embates político-partidários. $O$ foco e o caráter das lutas sociais deslocaram-se de forma crescente para batalhas com forte viés cultural, de onde emergiu também uma agenda renovada de temas e formas de manifestação. Ao mesmo tempo, diluíram-se rapidamente as fronteiras, até então bem demarcadas, entre as instâncias pública e privada da vida social, fenômeno mais tarde analisado por Sennett (1988) como o "declínio do homem público".

A reconfiguração em curso implicou na emergência de mobilizações que passaram a ser denominadas como os novos movimentos sociais. O interesse pelo tema continua central na pesquisa social e o fenômeno permanece como um desafio à ordem como "ações sociais coletivas de caráter sócio-político e cultural que viabilizam distintas formas da população se organizar e expressar suas demandas" (GOHN, 2003, p. 13).

Pesquisadores mobilizados pelo tema concordam que tais movimentos - urbanos por excelência e cada vez mais expressivos em termos numéricos - são realmente novos quando comparados aos movimentos sociais típicos da primeira metade do século $X X$. Caracterizados pela ausência de base social demarcada, por novos espaços de conflito e, ainda, por demandas metapolíticas, identidades plurais e um novo ativismo, essas mobilizações ocorrem fora da esfera institucional e buscam sensibilizar e persuadir a sociedade para sua transformação radical com base no diálogo da diversidade.

Boaventura Santos (2006, p. 258) enfatiza que esses movimentos advogam "um novo paradigma social" assentado "na cultura e na qualidade de vida", denunciando formas de opressão que atingem toda a sociedade. Para o autor,

as formas de opressão e de exclusão contra as quais lutam não podem, em geral, ser abolidas com a mera concessão de direitos, como é típico da cidadania; exigem uma 
reconversão global dos processos de socialização e de inculcação cultural e dos modelos de desenvolvimento [...] (SANTOS, 2006, p. 261).

Essa crise político-cultural teria sido deflagrada pelo movimento estudantil europeu da década de 1960, uma vez que as estruturas políticas tradicionais não acomodaram as novas demandas. Ao identificar múltiplas situações de opressão no cotidiano e ao enfatizar a necessidade de lutar por maiores espaços de participação política, o movimento estudantil iniciou a construção de uma nova cultura política a partir da politização do social, do cultural e do pessoal, abrindo possibilidades para o exercício de uma cidadania mais ampla, em substituição à chamada cidadania liberal, tida como limitada pois está centrada nos marcos do Estado.

Na América Latina, e no Brasil em particular, essas mobilizações assumiram caráter mais popular. Segundo Bertoncelo (2009), vivemos, ao final da década de 1970, um verdadeiro surto associativista: diversos segmentos sociais autônomos organizaram-se, pressionando o núcleo de poder e obrigando-o a maior sensibilidade frente às demandas da sociedade.

Estudiosos do tema, a exemplo de Boaventura Santos (1999 apud SANTOS, 2008), apontam para a existência de um certo hibridismo nos movimentos latino-americanos, uma impureza derivada da mistura de novos e velhos referenciais de luta, de demandas materiais e pós-materiais - demandas que não mais se reduzem às privações econômico-sociais, abrindo espaço para o enfrentamento das misérias subjetivas que têm desumanizado o Homem (MARTINS, 2000).

Em se tratando especificamente do Brasil, isso se explicaria pelas particularidades históricas de nossa sociedade, em comparação com a realidade dos países ditos centrais, onde a luta de classes assumiria caráter mais tênue perante a já consolidada democracia liberal. Para o autor,

provavelmente devido ao carácter semiperiférico da sociedade brasileira, combinam-se nela movimentos semelhantes aos que são típicos dos países centrais (movimento ecológico, movimento feminista - ainda que as reivindicações concretas sejam distintas), com movimentos próprios orientados para a reivindicação da democracia e das necessidades básicas (comunidades eclesiais de base, movimentos dos sem-terra, movimentos de favelados) (SANTOS, 2006, p. 265).

Partindo dessas premissas, apresentamos a seguir um breve panorama do (re)nascimento dos movimentos sociais no Brasil a partir da década de 1970 - momento em que outras possibilidades de transformação social pareciam inviáveis. Em seguida, trataremos mais especificamente do objeto da presente análise: a apreensão da Campanha Diretas, Já! enquanto movimento social híbrido. 


\section{Transição democrática e movimentos sociais no Brasil}

O processo de construção de uma nova ordem política em função do declínio de regimes autoritários conduz, necessariamente, a um processo de constituição de novos sujeitos e atores políticos. Nessa direção, a presente análise nos remete ao golpe militar de 1964, ao regime subsequente e aos movimentos sociais que atuaram no processo de superação do regime autoritário no período. Para Moura e Silva (2008), pode-se estabelecer uma relação de causa e efeito entre a mobilização de diversos setores sociais e o processo de redemocratização brasileiro. Os autores consideram que tais movimentos podem, de certo modo, ser vistos como elementos propulsores do processo de abertura, ao mesmo tempo em que também representaram uma efetiva renovação na dinâmica associativa da sociedade brasileira.

A questão tem sido recorrente na análise social com a perspectiva de avaliar, em profundidade, o papel dessas mobilizações não só na reconstrução mas também na consolidação da democracia brasileira. Ao que parece, a resposta a essa questão depende da análise das características dessas mobilizações, cujo ápice pode ser identificado na Campanha das Diretas de 1984, alvo central de nossa reflexão.

O processo brasileiro de transição rumo à democracia é visto como particular na América Latina, pois resultou de uma negociação entre elites e não de um choque político via deposição. Um elemento relevante do processo foi a profunda crise econômica - não apenas conjuntural, mas estrutural - que se abateu sobre o país na esteira da crise mundial deflagrada pelo 'choque do petróleo' em meados da década de 1970, e que acentuou as divergências que cindiam os militares enquanto bloco de poder hegemônico. Tomando como marco o ano de 1974 e a ascensão do general Ernesto Geisel ao Palácio do Planalto, poderemos acompanhar um longo período de corrosão do regime militar, que acabou por assumir a retórica da abertura política e postergou o fim da ditadura no Brasil.

Há certo consenso entre estudiosos sobre as características do regime autoritário no Brasil e seu processo de transição. Ancorado em êxitos econômicos decorrentes da intensa concentração de renda, e associado a um tipo de repressão em "menor escala" em comparação com os vizinhos do Cone Sul, o regime militar brasileiro construiu boa parte de sua legitimidade em setores das classes médias urbanas convencidas, de início, da iminente ameaça comunista. A retórica anticomunista assumiu vários contornos ao longo do regime e contribuiu para delimitar grupos e atores no interior do regime.

No decurso da transição para abertura política, os grupos anticomunistas mais radicais estiveram alijados das negociações; assim, o processo foi marcado por elevado grau de continuísmo do espectro conservador. Desse modo, os militares e seus aliados foram preservados política e juridicamente dos crimes cometidos no estado de exceção e 
diversos segmentos atuantes na ditadura asseguraram participação no regime que se constituiu no contexto pós-abertura.

Para tanto, tornou-se imperativo o controle do processo político e a contenção das mobilizações populares. Ao restringir o acesso de novos atores políticos e sua capacidade decisória, o grupo no poder interditou a representação política efetiva das grandes massas populares no regime que estava por ser iniciado. Em que pesem as estratégias de interdição, a abertura política viria a se constituir um terreno fértil para o renascimento e fortalecimento das lutas sociais no país. O longo processo de abertura política ocorreu, portanto, pari passu a uma gradual reconstrução da sociedade civil, com o surgimento de novos atores sociais e com a reconstituição das identidades coletivas, elemento primordial e leitmotiv dessas lutas.

As trilhas da redemocratização brasileira tornam ainda mais desafiador compreender a eclosão de um movimento como o das Diretas Já! Uma análise detida do processo permite amplificar a disputa entre duas posições em torno dos destinos da sociedade brasileira. De um lado, atores de um regime que muda para permanecer no controle. De outro, a manifestação altissonante de cidadãos que se reposicionam em relação à vida política, buscando $\mathrm{VOz}$ e voto no cenário nacional. Tinha início no Brasil um novo "tempo da política" (TEIXEIRA e CHAVES, 2004, p. 7).

\section{A década de 1970 e a luta por um novo Brasil}

Para o jornalista Ricardo Kotscho (1984), a década de 1980 consagra a explosão de um "novo Brasil" que se gestara nos anos anteriores. As lutas sociais renasceram e se propagaram pela década de 1980. Inicialmente tímidas e receosas, ganharam ritmo, dinâmica e abrangência. Suas raízes podem ser encontradas nas diferentes formas de resistência à truculência dos governos militares, aprendizagem fundamental para a retomada posterior dos espaços públicos, até então usurpados pela ditadura. Nessa perspectiva, Araújo afirma que

Esses novos atores eram produto dos anos de arbítrio, da experiência da sociedade em elaborar estratégias de enfrentamento à ditadura, numa condição totalmente diferente da experimentada antes de 64, e mesmo antes de 68. Esses novos atores eram os atores possíveis numa realidade de ditadura militar (ARAújO, 2007, p. 334).

Para Weffort (1984 apud SADER, 1988, p. 33) esse cenário permite a "descoberta da Sociedade Civil". Ou seja, a organização da sociedade civil como decorrência da demanda por participação política de movimentos sociais destituídos de espaços de atuação institucional. Ao superar o caminho da luta armada, assumido pela guerrilha urbana e rural entre o final da década de 1960 e meados da seguinte, os novos movimentos apresentaram um caráter mais pragmático. 
A partir de 1975, quando explodiram movimentos autônomos de contestação, a onda de reivindicações concentrava-se em questões cotidianas: Movimento do Custo de Vida, Movimento por Moradia, manifestações contra a espoliação urbana, a carestia, o empobrecimento resultantes, a priori, do modelo concentrador de renda, com um perfil nítido de demandas tradicionais.

Contudo, as necessidades imediatas não explicam, isoladamente, a eclosão dessas manifestações. Um aspecto relevante é a trajetória comum e a interação identitária desenvolvida entre os membros dos grupos mobilizados. Essa condição assegurou que se constituíssem formas cada vez mais elaboradas de atuação dos movimentos populares, cuja força colocava em xeque a condição de exclusão, contribuindo para o fortalecimento da sociedade civil, entendida como parte da esfera pública no contexto das relações político-sociais.

No interior dessa conjuntura, merecem destaque as greves operárias de 1978/79. O movimento operário recompunha-se desde o governo Geisel em um novo registro político, desvinculado do sindicalismo atrelado ao estado populista com origem na década de 1930. O então denominado "novo sindicalismo", cujas raízes remontam ao chão de fábrica, apresentava especificidades relevantes: independência em relação ao Estado, novas formas de organização e novas lideranças. Sua atuação se sustentava nos debates, nas comissões e comandos de greves desenvolvidas em grandes unidades industriais, em especial na região do $A B C$ paulista, berço de importantes centrais sindicais que permanecem em atuação ainda nos dias atuais.

Alimentados por um ideal de participação democrática, direta e autônoma, esse novo sindicalismo mobilizou, solidarizou e empolgou o operariado ao recompor sua identidade de classe. Em pouco tempo, o conflito operário supera o movimento sindical e o ambiente da fábrica e diferentes atores sociais vão assumindo a greve como expressão de algo mais abrangente, como expressão da luta democrática em curso.

No interior desse processo se desenvolveram novas identidades coletivas, pois o movimento operário não era um movimento isolado. As diferentes lutas vivenciadas significavam o aprendizado político na prática social, numa década de efervescência política na cidade e no campo. Reivindicações centradas, num primeiro momento, em questões específicas ou de caráter classista, acabaram por se ampliar de tal forma que dominaram o cenário político nacional, alterando a percepção do grupo e das classes dirigentes acerca da realidade.

Sem dúvida, a participação de milhares de pessoas até então excluídas de qualquer forma de identidade ou cidadania, através de movimentos sociais, [...] contribuiu para alargar a vida democrática local e para construir uma nova identidade para aquelas pessoas: a de cidadãos com direitos (GOHN, 2000, p. 155). 
Nas agitações vividas pelo país era possível observar a fusão entre as lutas ligadas ao ambiente do trabalho e a realidade cotidiana das populações mais carentes da periferia urbana. Santos (2008) destaca a atuação dos grupos que irromperam na cena pública: os problemas que afetavam o cotidiano popular ganharam dimensão política, permitindo a incorporação de novas forças sociais e de novas demandas, que confluíram para a luta pela redemocratização. A Campanha das Diretas seria o auge desse processo, aponta Rodrigues (2003, p. 11), a culminância de uma "revolução subterrânea".

Deflagrada em abril de 1983, ano em que se iniciou o debate acerca da sucessão presidencial do presidente Figueiredo, a Campanha pelas eleições diretas ganhou fôlego a partir de janeiro de 1984, às vésperas da votação da proposta de emenda constitucional do Deputado Federal Dante de Oliveiral/PMDB-GO, que determinava o restabelecimento de eleições diretas para presidente já em 1985. Reunindo um número cada vez mais expressivo de participantes, tornar-se-ia o coroamento de um processo de organização, conscientização e fortalecimento da sociedade civil.

Procurando captar esse hibridismo, por um lado, devemos buscar as permanências. Por outro, recuperar aspectos que o tornaram novo: a expressiva presença numérica, a ampliação dos espaços de luta, o caráter fundamentalmente coletivo e identitário, a imensa capacidade de mobilização e o grau de autonomia que o movimento alcançou.

\section{A campanha das Diretas: um movimento social híbrido}

Após um longo período de opressão política, a sociedade brasileira foi capaz de se reorganizar como sujeito coletivo em condições de apontar e promover mudanças. Em uma perspectiva antropológica estabeleceu sua condição de sujeito como decorrência de "práticas sociais e culturais que dão sentido de pertencimento [...]" (CANCLINI, 1997, p. 22). Para Sader (1988), a ação do sujeito coletivo emerge das condições criadas pelo próprio movimento popular, forjadas na experiência coletiva de luta, o que assegura o desenvolvimento de sua identidade coletiva. Estudantes, operários, intelectuais, sindicalistas, artistas, jogadores de futebol, em especial os cidadãos comuns, compuseram esse sujeito coletivo. Milhares de indivíduos anônimos, dispersos - em sua maioria sem envolvimento direto nas lutas políticas - nesse momento, na condição de sujeito plural e a partir de um agir comunicativo, assumiram, coletivamente, uma posição favorável à emenda Dante de Oliveira.

Nun (1989 apud MOURA e SILVA, 2008) qualifica esse agir coletivo de a rebelião do coro, ou seja, atores sociais tradicionalmente marginalizados da cena política se colocam como protagonistas da mudança, assumindo a convicção de que poderiam promover a reorganização do sistema político e a superação da realidade a partir do restabelecimento das eleições diretas. 
Para a maioria dos observadores desatentos, a mobilização popular pelas diretas e sua surpreendente consciência política foram uma grata surpresa, algo inesperado (na compreensão da elite dirigente, aparentemente sem raízes em movimentos anteriores) e que levou o governo a temer pela manutenção de sua propalada "ordem" no processo sucessório. Segundo Marcondes Filho (1989, p. 171) "ninguém previa a explosão tão intensa e enérgica das massas".

O novo ativismo pode ser identificado como socialização da política, conforme definição de Santos (2008). As manifestações pró-Diretas criaram novos ambientes para o exercício da política ao promoverem relações inesperadas com o espaço público, fazendo dos grandes centros urbanos do país seu palco mais ostensivo. As ruas tornaram-se espaços de demonstração do projeto político elaborado fora do sistema de representação tradicional e o entusiasmo da ação contagiava os cidadãos.

A convergência numérica e a tomada do espaço público fizeram surgir o sujeito coletivo com visibilidade pública. Na praça, "o lugar no qual o povo assume a voz que canta" (BAKHTIN, 1974 apud MARTÍN-BARBERO, 2006 , p. 101), surge a multidão, "uma realidade viva, forte, surpreendente, assustadora, deslumbrante" (IANNI, 1989, p. 5). Os comícios tornaram-se a principal forma de demonstração da vontade popular e a participação ativa nesses eventos configurou-se como elemento de pressão da sociedade pela aprovação da emenda Dante de Oliveira.

Contrário às afirmações desabonadoras em torno dos comícios, o que se via era uma campanha ordeira e disciplinada. Seus desdobramentos preocupavam os grupos dirigentes pela maturidade e envolvimento social inesperados; não se tratava de um movimento desprovido de consciência política. Sader destaca que

movimentações que antes podiam ocorrer de modo quase silencioso [...] passam a ser valorizadas enquanto sinais de resistência, vinculadas a outras num conjunto que Ihes dá a dignidade de um acontecimento histórico (SADER, 1988 , p. 12).

Ao se analisar a trajetória das mobilizações, desde o primeiro comício ocorrido em 15 de junho de 1983, em Goiânia, até o evento de 16 de abril de 1984, em São Paulo, na véspera da votação no Congresso, observa-se um tom cada vez mais ritualístico, cerimonioso e sentimental, como parte de um roteiro cívico: a abertura, a presença de artistas com grande apelo popular, os discursos sucessivos e o gran finale, quando os presentes entoavam, visivelmente emocionados, o hino nacional brasileiro.

Simmel (2006), entre outros, tem destacado o potencial político das manifestações sociais dos sentimentos que resultam em práticas e discursos capazes de ampliar os espaços de solidariedade e, portanto, a identidade coletiva e a força da reivindicação. Trata-se, nessa perspectiva, de um novo projeto emancipatório que parte da mobilização de diversos setores sociais, transcendendo suas esferas de atuação originais em 
grandes manifestações públicas e buscando produzir impacto e visibilidade através da mídia, meio decisivo de pressão política no espaço público contemporâneo.

O alto grau de envolvimento sentimental e essa visibilidade contribuem para transformar as mobilizações em grandes espetáculos modernos - e nesses

o agente do espetáculo levado à cena é o oposto do indivíduo [...]. Aparecendo no espetáculo como modelo de identificação, ele renunciou a toda qualidade autônoma para identificar-se com a lei geral de obediência ao desenrolar das coisas (DEBORD, 1997, p. 40).

A questão remete a outro aspecto central: o grau de autonomia do movimento. Do conjunto de comícios de 1984, destacam-se os realizados em São Paulo, no Rio e em Belo Horizonte. Em todos eles caracterizou-se o apoio dos governos estaduais que garantiram acesso, mobilidade, infraestrutura de palco e sistemas de som. Nesses comícios suprapartidários, além do cidadão comum, compareciam políticos e lideranças de expressão nacional como Ulysses Guimarães, Tancredo Neves, Fernando Henrique Cardoso, Franco Montoro, Lula. Dado o incontestável alcance popular, o PMDB procurou assumir a direção da campanha e lançou o movimento em nível nacional no comício de Goiânia.

O interesse dos governos estaduais da base oposicionista em arregimentar a massa tornou-se patente e a autonomia do movimento sofreu alguns questionamentos. Segundo Nery

uma campanha que nasce no seio do Parlamento e que é conduzida para aprovação, neste mesmo Parlamento, [...] tem seu limite imposto pelo próprio papel do Estado capitalista. Neste sentido, as classes dominantes brasileiras foram bastante eficientes, pois conseguiram dirigir um movimento de massas, que teve a presença de muitos milhões de pessoas nas ruas e praças, dentro de limites suficientemente estreitos para preservarem inteiramente os dispositivos de dominação capitalista na formação social brasileira (NERY, 2010, p. 118).

Pode-se argumentar que sua forma espetacular colaborou para obscurecer negociações entre grupos da situação e oposição. Nessas condições, Debord (1997), por exemplo, afirma ser mais fácil ocultar o centro diretor, favorecendo a disseminação da crença de que se trata de um movimento independente da sociedade e que essas figuras de renome nacional são apenas cidadãos comuns em congraçamento.

Contudo, a observação minuciosa demonstra que não se tratava de mobilização personalista e clientelista. Os novos atores incorporavam a si próprios como sujeitos históricos, independentes de um elemento que atuasse como suporte da ação política coletiva. Rodrigues (2003) destaca o 
editorial da Revista Veja que ressalta essa vontade coletiva: seria engano acreditar que a multidão se agrupa para se deixar convencer pelos discursos. Ao contrário, quer ser ouvida e convencer governo e Congresso sobre seu profundo desejo de escolher o presidente.

Para corroborar essa perspectiva de análise, deve-se ressaltar que o sujeito autônomo "não é aquele que seria livre de todas as determinações externas, mas aquele que é capaz de reelaborá-las em função daquilo que define como sua vontade" (SADER, 1988, p. 56).

Desse modo, ao superar cada vez mais seu caráter partidário, a par da presença de múltiplas representações civis organizadas - partidos políticos, igreja, sindicatos - a luta invadiu o cotidiano e a rotina dos cidadãos. Materializou-se em seu mundo privado, promovendo um envolvimento autônomo e contribuindo para diminuir o grau de controle de lideranças políticas ditas tradicionais.

Outro aspecto que reforça a tese da relativa autonomia é o temor que a campanha suscitou entre os opositores políticos reconhecidos pelo Estado. Com a proximidade da votação da emenda em 25 de abril de 1984, algumas lideranças tentaram promover o enfraquecimento da Campanha. Figuras influentes, como Tancredo Neves, se ausentaram dos comícios finais alegando ser necessário "evitar a radicalização que pode levar o País à situação de um retrocesso que gerará para o povo condições mais difíceis e penosas do que aquelas que ele enfrenta no momento"1.

Ainda assim, pesquisas mostravam que $80 \%$ dos brasileiros davam como certa a aprovação da emenda (COUTO, 2003). A convicção e a esperança mantiveram a força do movimento que reuniu mais de 1 milhão de pessoas nos comícios de São Paulo e do Rio de Janeiro, às vésperas da votação. A sociedade havia, de fato, "tomado a palavra de ordem Diretas Já como sua" (RODRIGUES, 2003, p. 102).

Para Meyer e Montes (1985), o povo mostrou-se capaz de romper a organização inicial, criar as próprias palavras de ordem que contaminaram seu universo particular e garantiram a identidade de indivíduos que buscavam liquidar o regime militar por ocasião da sucessão presidencial. Bertoncelo (2009) enfatiza que a luta penetrou na sociedade, que se envolveu emocionalmente. Assim, mesmo indivíduos que apenas acompanhavam os comícios pelos meios de comunicação sentiam-se ativos nesse capítulo da história nacional e faziam questão de demonstrar seu envolvimento vestindo verde e amarelo, as cores símbolo da campanha, pendurando fitas e bandeiras em carros e em janelas de casas e prédios. A solidariedade que o movimento despertou tornava desnecessária qualquer liderança formal e legitimava a reivindicação.

A mobilização desses novos atores e a gestação de um novo ativismo em uma ampla frente de luta democrática não implicou no

${ }^{1}$ Entrevista de Tancredo Neves à Folha de S. Paulo, 24 de abril de 1984. 
abandono das questões conjunturais que pesavam sobre o cotidiano. As eleições diretas apareciam como caminho para superação das demandas apresentadas; em última análise, seria a síntese de demandas materiais emergenciais, ligadas à sobrevivência, e pós-materiais. Segundo Gohn (2003, p. 18) "a partir das reivindicações dos movimentos sociais se vê expressada, também, a pluralidade de interesses, [...] onde ainda também se encontra o confronto da luta de classes".

Nesse sentido, a redemocratização é compreendida como caminho para alcançar a cidadania social, negada historicamente, e a cidadania política, ainda numa perspectiva de democracia representativa e não a democracia participativa ou direta.

Essa fusão não deve ser compreendida como "mera somatória de experiências" (KOWARICK, 1983 apud SADER, 1988, p. 312) e demandas, pois traz algo de novo e abre novas possibilidades para o futuro, sendo elemento essencial para a compreensão do hibridismo desses movimentos na América Latina, nos quais ainda se percebem latentes as velhas divergências de classes.

\section{Considerações Finais}

A mobilização e a força da Campanha Diretas Já! não garantiram a aprovação da Emenda Dante de Oliveira, derrotada por 22 votos. Seriam necessários 320 votos de um total de 479 congressistas. Prevaleceu a opção pela transição negociada, o que demonstra a enorme (e histórica) distância entre a voz das ruas e o Congresso. A partir de então, e superada a frustração da derrota, todos os olhares se voltaram para a sucessão por meio do Colégio Eleitoral. A Aliança Democrática, uma coligação PMDB/PFL - esse último formado por dissidentes do PDS que se opunham à candidatura de Paulo Maluf -, elegeu Tancredo Neves e José Sarney para conduzirem o Brasil na suposta reconstrução da democracia, até aqui limitada (ou confundida) com o restabelecimento do direito à participação política via voto.

A trajetória de luta da sociedade brasileira entre as décadas de 1970/1980 e o desfecho da mobilização pelas Diretas nos impõe algumas reflexões acerca das contribuições que essa experiência política tão profunda legou à cultura política nacional.

Segundo Boaventura Santos, os novos movimentos sociais

significaram uma ruptura com as formas organizativas e os estilos políticos hegemónicos e o seu impacto na cultura e na agenda política desses países transcende em muito as vicissitudes de trajectória dos movimentos em si mesmos (SANTOS, 2006, p. 268).

A priori, devemos destacar que a própria concepção de nação começava a ser reconstruída, tendo seu foco sido deslocado para a 
multidão concentrada nas praças exigindo cidadania. Para Chauí (1986 apud EUGÊNIO, 1995, p. 212) "a Nação não é, ela se faz". Em 1984, ela se fez exigindo um novo lugar na história ao entoar o hino nacional ao término de cada comício, sintetizando a vontade popular de se apropriar da pátria que lhe havia sido usurpada 20 anos antes.

Eugênio (1995) destaca alguns aspectos da realidade que emergia, nos permitindo delinear um novo comportamento político, processo no qual as Diretas teriam sido um elemento deflagrador. A mobilização de milhares de indivíduos, pessoas comuns e não necessariamente ligadas por um arcabouço ideológico, obrigou a uma releitura das concepções elitistas e tradicionais que viam o povo como massa apática e desqualificada.

A luta garantiu a união de diferentes atores e sedimentou a crença na reelaboração das práticas e da percepção política do cidadão comum, bem como no desenvolvimento de uma relação autônoma frente ao Estado, em substituição às experiências arcaicas de submissão ou cooptação. Desde então, novos espaços de atuação política no aparato estatal vem sendo assegurados, desde a conquista da Constituinte de 1988 e das eleições diretas em todos os níveis a partir de 1989, até experiências mais recentes de orçamentos participativos e conselhos municipais.

Para Dagnino (2004), sobrepujando o conceito liberal de cidadania, o país tem forjado uma cidadania ampliada que supera formas tradicionais de luta, modifica a cultura de direitos e expande o reconhecimento e a legitimidade de demandas muito mais amplas e subjetivas. Segundo a autora, essa nova cidadania considera a existência de um cidadão-sujeito, ativo e capaz de redefinir o próprio sistema político do qual pretende participar. A pressão exercida pela sociedade na crise do governo Collor, e o subsequente impeachment, exemplificam a afirmação de Dagnino. A mobilização madura e consistente deixou claro o esgotamento do velho modelo político personalista e permissivo.

Em substituição a uma tradição autoritária e hierarquizada, pode-se apontar para a consecução de uma nova cultura política, cujo resultado mais amplo deve ser a construção de uma sociabilidade também nova, pautada na reconfiguração da "dimensão ética da vida social" (DAGNINO, 2004, p. 208). Argumentos contrários, como de Brotto (2009), consideram que o país não superou suas formas tradicionais de fazer política. Para Rodrigues (2003) a chamada democracia política que foi se estruturando ao longo das lutas referidas teve, ela própria, um caráter híbrido: combinou a abertura de novos espaços políticos e a permanência de instituições, práticas e lideranças autoritárias.

Os sinais são contraditórios, assim como a própria experiência de construção da prática política. Contudo, nos interessa capturar e analisar os movimentos e articulações que permitem novos direcionamentos ainda que sua existência conviva com práticas aparentemente incompatíveis ou inconciliáveis. Desse modo constituem-se fenômenos híbridos porquanto portadores do novo, embora imersos em práticas 
arcaicas que resistem ao poder transformador que emerge das mobilizações sociais.

Sonale Diane Pastro Oliveira é Mestranda em Ciências Humanas e Sociais pela Universidade Federal do ABC/UFABC. Graduada e Licenciada em História pela Universidade de São Paulo/USP.

E-mail: sonale.pastro@ufabc.edu.br

Gabriela da Silva Martins da Cunha Marinho é Professora Doutora da Universidade Federal do ABC (UFABC) - Centro de Engenharia, Modelagem e Ciências Sociais Aplicadas, Santo André, São Paulo, Brasil.

E-mail: gabriela.marinho@ufabc.edu.br

\section{Referências}

ARAÚJO, Maria Paula Nascimento. Lutas democráticas contra a ditadura. In: FERREIRA, Jorge; REIS, Daniel Aarão (Orgs.). Revolução e democracia. Rio de Janeiro: Civilização Brasileira, 2007. p. 321-353.

BELL, Daniel. O Advento da Sociedade Pós-Industrial: uma tentativa de previsão social. São Paulo: Cultrix, 1977.

BERTONCELO, Edison Ricardo. Eu quero votar para presidente: uma análise sobre a Campanha das Diretas. Lua Nova, São Paulo, n. 76, p. 169-196, 2009.

BROTTO, Marcio Eduardo. Cultura Política: críticas, expressões e influências. Revista ComUnigranrio, Rio de Janeiro, v. 1, n. 1, p. 1-18, 2009.

CANCLINI, Nestor. Consumidores e Cidadãos. Rio de Janeiro: UFRJ, 1997.

COUTO, Ronaldo Costa. História Indiscreta da ditadura e da abertura Brasil 1964. Rio de Janeiro: Record, 2003.

DAGNINO, Evelina. Confluência Perversa, Deslocamento de Sentido, Crise Discursiva. In: GRIMSON, Alejandro (Org.). La cultura en las crisis latinoamericanas. Buenos Aires: Clacso, 2004. p. 195-216.

DEBORD, Guy. A sociedade do espetáculo. Rio de Janeiro: Contraponto, 1997.

EUGÊNIO, Marcos Francisco. Representações Políticas no Movimento Diretas Já. Revista Brasileira de História, São Paulo, v. 15, n. 29, p. 207219, 1995. 
GOHN, Maria da Glória. Movimentos sociais no início do século XXI: antigos e novos atores sociais. Petrópolis: Vozes, 2003.

IANNI, Octávio. A Sociologia e o mundo moderno. Tempo Social, São Paulo, v. 1, n. 1, p. 7-27, jan.-jun. 1989.

KOTSCHO, Ricardo. Explode um novo Brasil: Diário da campanha das Diretas. São Paulo: Brasiliense, 1984.

MARCONDES FILHO, Ciro. O capital da notícia. Jornalismo como produção social de segunda natureza. São Paulo: Ática, 1989.

MARTÍN-BARBERO, Jesus. Dos meios às mediações: Comunicação, cultura e hegemonia. Trad. Ronald Polito e Sérgio Alcides. Rio de Janeiro: UFRJ, 2006.

MARTINS, José de Souza. As mudanças nas relações entre a sociedade e o Estado e a tendência à anomia nos movimentos sociais e nas organizações populares. Revista Estudos Avançados, São Paulo, v. 14, n. 38, p. 268278, jan.-abr. 2000.

MEYER, Marlyse; MONTES, Maria Lúcia. Redescobrindo o Brasil: a festa na política. São Paulo: T. A. Queiroz, 1985.

MOURA, Tereza Vaz de; SILVA, Marcelo Kunrath. Atores sociais em espaços de ampliação da democracia. Revista de Sociologia e Política, Curitiba, v. 16, n. supl., p. 43-54, ago. 2008.

NERY, Vanderlei Elias. Diretas Já: a busca pela democracia e seus limites. In: Simpósio Lutas Sociais na América Latina, IV., Londrina, 2010.

RODRIGUES, Alberto Tosi. Diretas Já, o grito preso na garganta. São Paulo: Perseu Abramo, 2003.

SADER, Eder. Quando novos personagens entram em cena. Experiências e lutas de trabalhadores da grande São Paulo 1970 - 1980. Rio de Janeiro: Paz e Terra, 1988.

SANTOS, Boaventura. Pela mão de Alice. O social e o político na pósmodernidade. São Paulo: Cortez, 2006.

SANTOS, Regina Bega dos. Movimentos sociais urbanos. São Paulo: Editora Unesp, 2008. 
SENNETT, Richard. O Declínio do Homem Público: as tiranias da intimidade. São Paulo: Companhia das Letras, 1988.

SIMMEL, Georg. Questões Fundamentais da sociologia: indivíduo e sociedade. Rio de Janeiro: Jorge Zahar, 2006.

TEIXEIRA, Carla Costa; CHAVES, Christine de Alencar (Orgs.). Espaços e Tempos da Política. Rio de Janeiro: Relume Dumará, Núcleo de Antropologia da Política/UFRJ, 2004.

Texto recebido em 11/08/2012.

Aprovado em 22/11/2012. 